\title{
PENGARUH TERAPI MUSIK TERHADAP TINGKAT KONSENTRASI PADA ANAK AUTIS DI SDLB NEGERI 2 PANGKALAN BUN
}

\author{
${ }^{1}$ Rahaju Ningtyas \\ STIKes Borneo Cendekia Medika Pangkalan Bun \\ ${ }^{1}$ Email ningtyasrahaju @ gmail.com
}

\begin{abstract}
ABSTRAK
Memiliki anak yang cerdas secara spiritual, emosional dan intelektual adalah dambaan bagi setiap orang tua. Namun tidak semua anak mengalami perkembangan normal. Banyak diantara mereka yang dalam perkembangannya mengalami hambatan, gangguan, kelambatan, atau memiliki faktor-faktor resiko sehingga untuk mencapai perkembangan optimal diperlukan penanganan atau intervensi khusus. Penelitian ini berbentuk pre eksperimental dengan pendekatan one group pretest posttest. Populasi dari penelitian ini sebanyak 17 responden. Teknik pengambilan sampel adalah total sampling. Variabel independen dari penelitian ini adalah terapi musik dan variabel dependen adalah tingkat konsentrasi pada anak autis. Alat ukur yang digunakan adalah pedoman terapi musik dan lembar kuesioner, kemudian pengolahan data dimulai dari editing, coding, scoring, dan tabulating. Analisa data yang digunakan adalah uji Wilcoxon $(\alpha=0,05)$. Hasil penelitian didapatkan, tingkat konsentrasi sebelum terapi musik responden yang memiliki tingkat konsenterasi pada kategori sedang berjumlah 13 orang $(76,5 \%)$ dan yang memiliki kategori tinggi berjumlah 4 orang $(23,5 \%)$. Setelah dilakukan terapi musik responden yang memiliki tingkat konsenterasi pada kategori sedang berjumlah 11 orang $(64,7 \%)$ dan yang memiliki kategori tinggi berjumlah 6 orang (35,3\%). Hasil uji Wilcoxon menunjukkan $\mathrm{p}=0,000$ yang menunjukkan bahwa $\mathrm{p}<0,05$. Kesimpulan dari penelitian ini adalah ada pengaruh terapi musik terhadap tingkat tingkat konsenterasi pada anak autis di SDLB.
\end{abstract}

Kata kunci: Terapi Musik, Konsentrasi

\section{THE EFFECT OF MUSIC THERAPY ON THE CONCENTRATION LEVEL IN AUTHENTIC CHILDREN IN SDLB NEGERI 2PANGKALAN BUN}

\begin{abstract}
Having children who are spiritually, emotionally and intellectually intelligent is a dream for every parent. But not all children experience normal development. Many of those who experience development experience obstacles, disturbances, delays, or have risk factors so that to achieve optimal development requires special handling or intervention. The design of this study was pre experimental with one group pretest posttest approach. The population of this study was 17 respondents. The sampling technique is total sampling. Independent variable of this research is musik therapy and dependent variable is level of concentration. The measuring tools used are music therapy guidelines and observation sheet, then data processing starts from editing, coding, scoring, and tabulating. The data analysis used is Wilcoxon test $(\alpha=0,05)$. The results of the study the level of concentration before music therapy respondents
\end{abstract}


who have a level of concentration in the medium category amounted to 13 people (76.5\%) and those who had a high category amounted to 4 people (23.5\%). After doing music therapy respondents who have a level of concentration in the medium category numbered 11 people (64.7\%) and those who had a high category numbered 6 people $(35.3 \%)$. Wilcoxon test results showed $p=0,000$ which indicates that $p$ $<0.05$. The conclusion of this study is that there is an effect of music therapy on the level of concentration in autistic children in SDLB.

Keywords: musik therapy, concentration

\section{PENDAHULUAN}

\begin{abstract}
Memiliki anak yang cerdas secara spiritual, emosional dan intelektual adalah dambaan bagi setiap orang tua. Namun tidak semua anak mengalami perkembangan normal. Banyak diantara mereka yang dalam perkembangannya mengalami hambatan, gangguan, kelambatan, atau memiliki faktor-faktor resiko sehingga untuk mencapai perkembangan optimal diperlukan penanganan atau intervensi khusus. Kelompok inilah yang kemudian dikenal sebagai anak berkebutuhan khusus.
\end{abstract}

Permasalahan yang dihadapi di kelas anak autis adalah sebagian besar anak-anak tidak bisa duduk diam untuk berkonsenterasi, anak banyak bergerak kesana kemari, bicara sendiri, dan mengganggu temannya. Konsentrasi anak sangat diperlukan, baik dalam proses belajar maupun dalam menyelesaikan tugas-tugas lain. Dengan konsentrasi, anak dapat fokus mengerjakan tugas yang diberikan oleh gurunya sehingga pekerjaan itu mampu tuntas diselesaikannya dalam waktu tertentu. Tanpa ada dukungan konsentrasi seorang anak tidak akan mampu menyelesaikan setiap tugas yang diberikan oleh gurunya dengan baik atau dapat menyelesaikan tugas tersebut tetapi dalam waktu yang lama.
Data dari UNESCO pada tahun 2011 tercatat 35 juta orang penyandang autisme di seluruh dunia. Ini berarti rata-rata 6 dari 1000 orang di dunia mengidap autisme. Hasil penelitian Center for Disease Control (CDC) di Amerika pada tahun 2008 menyatakan bahwa perbandingan autisme pada anak umur 8 tahun yang terdiagnosa dengan autisme adalah 1:80. Penelitian di Hongkong Study pada tahun 2008 melaporkan tingkat kejadian autisme di Asia prevalensinya mencapai 1,68 per 1000 untuk anak di bawah 15 tahun. Di Indonesia prevalensi autisme 1,68 per 1000 untuk anak di bawah 15 tahun dimana jumlah anak usia 5-19 tahun di Indonesia mencapai 66.000.805 jiwa berdasarkan data BPS tahun 2010 maka diperkirakan terdapat lebih dari 112.000 anak penyandang autisme pada rentang usia 5-19 tahun

Untuk mengatasi berdaya konsentrasi rendah tersebut, banyak cara yang bisa digunakan misalnya modifikasi diet, olah raga, terapi warna, biofeed back, obat yang dibuat khusus, memulihkan energi dan memperbaiki jalur pendengaran. Penulis mencoba menggunakan pendekatan alternatif untuk meningkatkan konsentrasi anak melalui jalur pendengaran. Upaya yang dilakukan adalah dengan memperdengarkan musik, sesuai dengan jenis musik yang diminati. Dengan harapan bahwa terapi musik dapat membantu memulihkan kapasitas 
pendengaran / penerimaan suara, sehingga anak dapat belajar terfokus dan menangkap suara yang diinginkan langsung ke pusat bahasa di otak. Oleh karena itu penulis tertarik untuk melakukan penelitian lebih lanjut tentang "Pengaruh musik klasik terhadap tingkat konsenterasi pada anak autis di SLB Negeri 2 Pangkalan Bun Tahun 2018

\section{METODE PENELITIAN}

Jenis penelitian ini adalah pre eksperimental dengan desain one group pretest post test (Kasiran, didalam Sujarweni, 2014, 179). Populasi pada penelitian ini adalah seluruh anak autis yang berada di SDLB Negeri 2. Total sampling digunakan sebagai teknik sampling dengan jumlah sampel 17 responden. Variabel Independen penelitian ini adalah terapi musik dan variabel dependen adalah tingkat konsentrasi anak autis. Alat pengumpulan data berupa lembar observasi dan pedoman terapi musik Lembar observasi berisikan data umum (Usia, Jenis Kelamin)

\section{HASIL PENELITIAN}

Tabel 1 Distribusi frekuensi berdasarkan umur

\begin{tabular}{llcc}
\hline N & Umur & $\begin{array}{l}\text { Freku } \\
\text { ensi }\end{array}$ & $\begin{array}{l}\text { Persent } \\
\text { ase }\end{array}$ \\
\hline 1 & 6-11 Thn & 11 & 64,7 \\
2 & $12-14$ Thn & 1 & 5,9 \\
3 & $15-17$ Thn & 5 & 29,4 \\
\hline & Total & 17 & 100 \\
\hline
\end{tabular}

Sumber: Data primer 2018

Tabel 1 Berdasarkan tabel di atas diketahui bahwa frekuensi terbesar pada responden memiliki umur 6-11 tahun berjumlah 11 orang $(64,7 \%)$ dan yang terkecil pada umur 12-14 tahun berjumlah 1 orang $(5,9 \%)$

Tabel 2 Distribusi frekuensi berdasarkan jenis kelamin

\begin{tabular}{ccc}
\hline Jenis Kelamin & $\mathrm{N}$ & $\%$ \\
\hline Laki-laki & 8 & 47,1 \\
Perempuan & 9 & 52,9 \\
\hline Jumlah & 17 & 100 \\
\hline Sumber: Data primer 2018 &
\end{tabular}

Tabel 2 menunjukkan bahwa sebagian besar anak berjenis kelamin perempuan sebanyak 9 anak (52,9\%).

Tabel 3 Distribusi frekuensi berdasarkan tingkat konsentrasi sebelum (pre test)

\begin{tabular}{llcc}
\hline N & Tingkat & Freku & $\begin{array}{l}\text { Persent } \\
\text { onsi }\end{array}$ \\
o. & Konsentrasi & ase \\
\hline 1 & Rendah & 0 & 0 \\
2 & Sedang & 13 & 76,5 \\
3 & Tinggi & 4 & 23,5 \\
\hline & Total & 17 & 100 \\
\hline
\end{tabular}

Sumber: Data primer 2018

Tabel 3 menunjukkan bahwa sebelum dilakukan terapi musik klasik responden yang memiliki tingkat konsenterasi pada kategori sedang berjumlah 13 orang $(76,5 \%)$ dan yang memiliki kategori tinggi berjumlah 4 orang $(23,5 \%)$.

Tabel 4 Distribusi frekuensi berdasarkan tingkat konsentrasi sesudah (post test) pemberian terapi musik

\begin{tabular}{|c|c|c|c|}
\hline $\begin{array}{l}\mathrm{N} \\
\mathrm{O} .\end{array}$ & $\begin{array}{l}\text { Tingkat } \\
\text { Konsentrasi }\end{array}$ & $\begin{array}{l}\text { Freku } \\
\text { ensi }\end{array}$ & $\begin{array}{l}\text { Persent } \\
\text { ase }\end{array}$ \\
\hline 1 & Rendah & 0 & 0 \\
\hline 2 & Sedang & 11 & 64,7 \\
\hline
\end{tabular}




\begin{tabular}{cccc}
3 & Tinggi & 6 & 35,3 \\
\hline & Total & 17 & 100 \\
\hline
\end{tabular}

Sumber: Data primer 2018

Tabel 4 menunjukkan bahwa setelah dilakukan terapi musik klasik responden yang memiliki tingkat konsenterasi pada kategori sedang berjumlah 11 orang $(64,7 \%)$ dan yang memiliki kategori tinggi berjumlah 6 orang $(35,3 \%)$

Tabel 5 Pengaruh terapi musik terhadap tingkat konsentrasi pada anak autis

\begin{tabular}{crccc}
\hline Tingkat & \multicolumn{2}{c}{ Pretest } & \multicolumn{2}{c}{ Post test } \\
\cline { 2 - 5 } konsentrasi & $\mathrm{N}$ & $\%$ & $\mathrm{~N}$ & $\%$ \\
\hline Rendah & 0 & 0 & 0 & 0 \\
Sedang & 13 & 76,5 & 11 & 64,7 \\
Tinggi & 4 & 23,5 & 6 & 35,3 \\
\hline Jumlah & 17 & 100 & 17 & 100 \\
\hline \multicolumn{6}{c}{ Uji wilcoxon } & $\mathrm{p}=0.049$ & \\
\hline
\end{tabular}

Berdasarkan hasil analisis menggunakan SPSS 16, didapatkan hasil uji wilcoxon adalah 0,049 , hal ini menunjukkan nilai $\mathrm{p}<0,05$ maka $\mathrm{H} 1$ diterima dan $\mathrm{H} 0$ di tolak, atau dengan kata lain ada pengaruh terapi musik terhadap tingkat konsentrasi pada anak autis di SDLB Negeri 2 Pangkalan Bun

\section{PEMBAHASAN}

\section{Tingkat konsentrasi pemberian terapi musik}

sebelum

Tabel 3 menunjukkan bahwa tingkat konsentrasi sebelum pemberian terapi musik (pretest), sebagian besar anak memiliki tingkat konsentrasi sedang sebanyak 13 anak (76,5\%).

Peneliti berasumsi Konsentrasi anak autis ini juga dapat dipengaruhi oleh berbagai faktor antara lain seperti faktor psikis dimana konsentrasi anak autis berkurang akibat keadaan psikis penderita, bagi siswa SLB yang secara emosional tidak stabil dan tidak mendapat penerangan yang baik pada umumnya memiliki konsentrasi yang rendah.

\section{Tingkat konsentarsi sesudah pemberian terapi musik}

Tabel 4 menunjukkan bahwa tingkat konsentrasi sesudah pemberian terapi musik (postest), sebagian besar anak memiliki tingkat konsentrasi sedang sebanyak 11 anak $(64,7 \%)$.

Peneliti berasumsi bahwa tingkat konsentrasi dapat bertambah karena terdapat faktor relaksasi. Saat mendengarkan musik yang dilagukan dengan baik maka akan menimbulkan rasa nyaman dan tenang.

Hal ini sejalan dengan penelitian Yolanda dan Yunita $(2015,7)$ yaitu terapi murottal dapat membuat perasaan menjadi tenang atau rileks, mengalihkan perhatian dari rasa tegang, takut, cemas, dan perbaikan sistem kimia tubuh yang dapat menurunkan tekanan darah serta dapat menurunkan aktivitas gelombang otak, memperlambat pernafasan, detak jantung, denyut nadi. Pernafasan yang lebih lambat dan dalam sangat baik untuk menimbulkan perasaan tenang, pengendalian emosi yang lebih baik, pemikiran yang lebih dalam dan metabolisme tubuh akan menjadi lebih baik. Alkahel 2011 dikutip dari (Handayani et all, 2012, 127), juga menyebutkan bahwa bacaan Al Quran yang dilagukan dengan baik memiliki efek relaksasi yang cukup besar yaitu $65 \%$. Terapi murottal dapat mengaktifkan sel-sel tubuh dengan 
menjadikan suara menjadi gelombang yang diterima tubuh, menurunkan respon reseptor nyeri dan otak akan mengeluarkan penghilang nyeri opioid natural endogen. Opioid ini bekerja dengan cara menghambat nosiseptor nyeri.

\section{Pengaruh terapi musik terhadap tingkat konsentrasi pada anak autis}

Tabel 5 menunjukkan, hasil analisis uji wilcoxon menggunakan SPSS 16 adalah 0,049. Hasil analisis statistik yang dilakukan menggunakan uji Wilcoxon dimana $\mathrm{p}=0,049$ maka $\mathrm{p}=<$ 0,05 yang artinya hipotesis peneliti terbukti bahwa terdapat pengaruh terapi musik terhadap tingkat konsentrasi pada anak autis di SDLB Negeri 2 Pangkalan Bun. Data yang diperoleh dari 17 responden setelah dilakukan terapi musik menunjukkan bahwa responden dengan tingkat konsentrasi sedang naik ke tingkat konsentrasi tinggi sebanyak 2 orang.

Peneliti berpendapat terapi musik memiliki pengaruh terhadap tingkat konsentrasi pada anak autis. Mereka yang didengarkan musik klasik dengan irama dan bacaan yang baik akan merasa tenang dan rileks. Hal ini dikarenakan saat seseorang didengarkan musik akan menstimulasi otak untuk menghasilkan hormon yang berperan untuk meningkatkan konsentrasi alami yaitu beta endorphin.

Berger (1992) menyatakan agama/kepercayaan mempengaruhi konsentrasi anak autis seperti dalam agama Islam, konsentrasi dapat dilatih dengan melakukan ritual pendekatan diri dan melaksanakan dzikir secara teratur. Hasil penelitian menunjukkan sebagian besar responden memiliki konsentrasi pada tingkat sedang, hal ini disebabkan karena ada pengaruh unsur keagamaan dimana seorang muslim akan senantiasa berusaha melaksanakan kewajiban untuk melaksanakan sholat dan berdzikir yang pada akhirnya akan mempengaruhi konsentrasi anak autis

\section{KESIMPULAN DAN SARAN}

\section{Kesimpulan}

1. Tingkat konsentrasi sebelum terapi musik (pretest) yaitu sebagian besar anak memiliki tingkat konsentrasi sedang sebanyak 13 anak.

2. Tingkat konsentrasi sesudah terapi musik (posttest) yaitu sebagian besar anak memiliki tingkat konsentrasi sedang sebanyak 11 anak.

3. Ada pengaruh terapi musik terhadap tingkat konsentrasi pada anak autis di SDLB Negeri 2 Pangkalan Bun.

\section{Saran}

1. Peneliti selanjutnya

Diharapkan peneliti selanjutnya dapat menjadikan penelitian ini sebagai rujukan dan sumber informasi serta dapat membandingkan efektifitas berbagai bentuk terapi nonfarmakologis seperti terapi musik dan audio lainnya dalam mengurangi nyeri.

\section{DAFTAR PUSTAKA}

Akmal, Mutaroh, et all. 2016. "Ensiklopedi Kesehatan". Yogyakarta: Ar-ruzz Media.

Durkin, M. 2010. Maternal Ages with Autism Specturm Disorder, Wisconsin.

Hardywinoto \& Setiabudi, Toni. (2002). Anak Unggul Berotak 
Prima. Jakarta: Gramedia Pustaka Utama

Handayani, et all. 2012. "Pengaruh Terapi Murottal Al Quran untuk Penurunan Nyeri Persalinan dan Kecemasan pada Ibu Bersalin Kala 1 Fase Aktif". Jurnal Ilmiah Kebidanan, Vol. 5 No. 2, hal. 115

Satiadarma, Monty P., \& Zahra, Roswiyani P. (2004). Cerdas dengan Musik.Jakarta: Puspa Swara.

Rudolph, A.M., Hoffman, J.I.E., Rudolph, C.D., 2006. Buku Ajar Pediatri Rudolph.Volume 1. Pediatri Perkembangan Perilaku. Jakarta: EGC, 141-143.

Nelson. (2007). Ilmu Kesehatan Anak. Jakarta : EGC.

Merritt, Stephanie. (2003). Simfoni Otak. Bandung : Kaifa. 